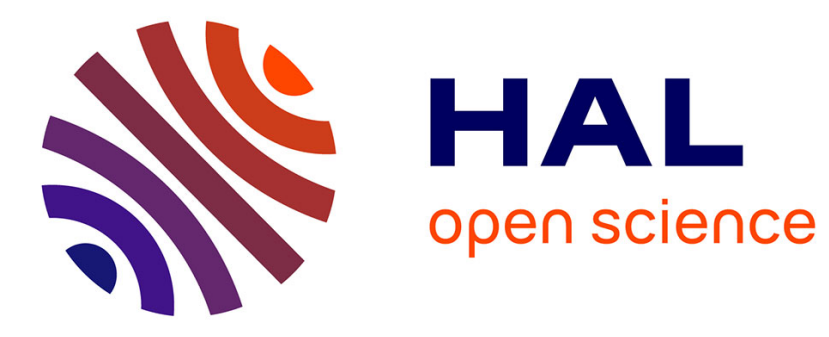

\title{
MOFs industrialization: a complete assessment of production costs
}

Maria Inês Severino, Effrosyni Gkaniatsou, Farid Nouar, Moisés L Pinto, Christian Serre

\section{- To cite this version:}

Maria Inês Severino, Effrosyni Gkaniatsou, Farid Nouar, Moisés L Pinto, Christian Serre. MOFs industrialization: a complete assessment of production costs. Faraday Discussions, 2021, 231, pp.326 - 341. 10.1039/d1fd00018g . hal-03429537

\section{HAL Id: hal-03429537 https://hal.science/hal-03429537}

Submitted on 16 Nov 2021

HAL is a multi-disciplinary open access archive for the deposit and dissemination of scientific research documents, whether they are published or not. The documents may come from teaching and research institutions in France or abroad, or from public or private research centers.
L'archive ouverte pluridisciplinaire HAL, est destinée au dépôt et à la diffusion de documents scientifiques de niveau recherche, publiés ou non, émanant des établissements d'enseignement et de recherche français ou étrangers, des laboratoires publics ou privés. 


\title{
MOFs industrialization: a complete assessment of production costs
}

Received 00th January 20xx, Accepted 00th January 20xx DOI: $10.1039 / \times 0 \times x 00000 x$

\begin{abstract}
Maria Inês Severino ${ }^{\mathrm{a}, \mathrm{b}}$, Effrosyni Gkaniatsou ${ }^{\mathrm{a}}$, Farid Nouar ${ }^{\mathrm{a}}$, Moisés L. Pinto ${ }^{\mathrm{b}}$, Christian Serre ${ }^{\mathrm{a}}$
The potential of safe and low-cost batch production process of Metal-Organic Frameworks (MOFs) at an industrial scale has been evaluated based on the prototypical MOF MIL-160(AI), a bio-derived material of a high practical interest that can be made with a high space-time yield using green ambient pressure conditions. A simple method to calculate the production cost of this material has been determined based on a simulated process constructed with the data collected from laboratory pilot large-scale tests taking into account for the first time in MOF cost evaluation all the process parameters such as the scale, cost of raw-materials, recirculation, and washing. The investment for a production plant established the ground for the estimation of the complete cost. The expected cost ranged from ca. $55 \$ / \mathrm{kg}$ at 100 tons/year down to $29.5 \$ / \mathrm{kg}$ for 1 kton/year production with longer term perspectives of reaching costs below $10 \$ / \mathrm{kg}$ once the bio-derived ligand is considered for the large-scale production of bioplastics.
\end{abstract}

\section{Introduction}

Metal-organic frameworks (MOFs) are a class of hybrid crystalline porous solid materials. ${ }^{1,2}$ Due to their large structural and functional tunability, leading in some cases to unprecedented porosity and surface area, MOFs have gained an increasing importance in the field of porous solids. ${ }^{3}$ Their new properties have unlocked a broad spectrum of potential applications in different areas, from gas storage and separation, catalysis, chemical sensing, proton conductivity and biomedicine. ${ }^{4}$ MOFs commercialization has started but there are still important steps to address prior to their integration into broad industrial applications. This calls from one side for the development of pilot-scale evaluation under industrially feasible operating conditions and, on the other side, for preliminary economical assessments. For instance, chemical engineering economical assessment of the MOF industrial production feasibility is an important prerequisite. Herein, we report a comprehensive methodology to simulate the large-scale MOF production cost based on existing data collected from lab pilot-scale systems.

The different assessments (production feasibility and economical) required for industrial production are studied at different scales of production. ${ }^{5}$ At the laboratory scale (milligram to gram scale), researchers do not typically focus on the optimization in terms of energy use, chemical toxicity, and synthesis processes, as the usual

\footnotetext{
a. Institut des Matériaux Poreux de Paris (IMAP), UMR 8004 CNRS, Ecole Normale Supérieure de Paris, Ecole Supérieure de Physique et de Chimie Industrielles de Paris, PSL Research University, 75005 Paris, France

b.CERENA, Departamento de Engenharia Química, Instituto Superior Técnico, Universidade de Lisboa, Av. Rovisco Pais, 1049-001 Lisboa, Portugal.

† Footnotes relating to the title and/or authors should appear here.

Electronic Supplementary Information (ESI) available: [details of any supplementary information available should be included here]. See DOI: 10.1039/x0xx00000x
}

target is to obtain pure, well crystalline compounds and assess their properties. To bridge the lab-scale to pilot and industrial-scale, the scale-up optimization at a larger scale must be considered, e.g. kilogram level, using laboratory equipment. This step is often addressed either at the academic or industrial level leading to samples produced at $100 \mathrm{~g}$ to a few $\mathrm{kg}$ scale. At this stage, key synthesis parameters are taken into account, as well as, the performance of the material obtained at larger scale that should be as close as possible to the small-scale sample. A great amount of optimization efforts is conducted during this key step prior to further industrial manufacturing development and optimization. This production scale yields enough material for specific and necessary industrial prototype tests, which is an essential step preceding possible industrial applications.

The space-time yield, STY, is one of the main parameters to consider during the synthesis optimization step. This parameter is defined as the quantity of MOF generated in a reactor per unit time and volume, e.g., kilogram of MOF per cubic meter per day, and allows for the evaluation of the large-scale production potential. Therefore, a high value indicates a high industrial potential. Several parameters can be tuned to reach the highest STY, such as concentration and reaction time while necessarily maintaining the highest yield. Process optimization should comprise several efforts beyond maximizing the STY, it should also focus on finding more economic, efficient, safe, and ecological conditions while maintaining a high purity/quality of the product required. ${ }^{6-8}$ Different production processes can be considered for MOF production both in batch or in continuous mode (mechanochemistry, microwave, sonochemistry, spray drying, or hydro/solvothermal etc.). However, upon upscaling some challenges must be overcome such as cost of equipment or ligand solubility. Depending on the material to be prepared, a balance has to be found between product quality, STY and cost. Herein we focus on a batch 
scale synthesis at ambient pressure using green solvent. ${ }^{9,10}$ Furthermore, the type of solvent employed is of great importance to the process, in regards to safety, legal and economic limitations. The use of so called "green" solvents (i.e. non-toxic, non-flammable, and environmentally friendly) are preferable for economically favorable processes. ${ }^{6-8,11-14}$ However, most MOF syntheses involve the use of toxic solvents such as amide based or hydrocarbon solvents, that have high polarity and high solubility capacity of the linkers. ${ }^{7,8,15}$ The use of such solvents requires very strict safety precautions, making the process unsuitable or very challenging to operate at pilot or industrial scale. ${ }^{16}$ Developing aqueous-based synthesis at ambient pressure represents one of the most efficient approaches towards green, low cost, and scalable synthesis of MOFs. ${ }^{8}$ The solvent replacement with greener options has already been reported for several benchmark MOFs. Furthermore, the environmental impact and the production costs can be reduced by a careful choice of the type and amount of chemical precursors. ${ }^{7,8,24,15,17-23}$ Linkers that are synthesized on a large-scale to be used in industry have attractive prices, e.g. benchmark aromatic polycarboxylic acids such as fumaric, trimesic, isophthalic, or terephthalic acids. ${ }^{25}$ The use of bio-sourced or bio-mass derived linkers is even more favorable since these linkers exhibit a minimal environmental impact being usually more soluble in water and sometimes cheaper. ${ }^{7,15,26}$ Additives can also be considered for solubility improvement, increasing the STY.$^{7,27}$ However, evaluation of higher process complexity (e.g. additional recirculation steps) or increase in material costs must also be taken into account. ${ }^{7,27}$ The same comment is valid for the metal precursor that shall be thoroughly considered. It is commonly admitted that high valence metal ions MOFs exhibit higher chemical stabilities than divalent cation MOFs since they form stronger metal-oxo/hydroxo bonds, therefore, they are attractive candidates for real applications. Metal ions that can be considered for the production of chemically stable MOF are, for example, $\mathrm{Al}^{3+}, \mathrm{Fe}^{3+}, \mathrm{Zr}^{4+}, \mathrm{Ti}^{4+}, \mathrm{Cu}^{2+}, \mathrm{Zn}^{2+}$, etc. ${ }^{7,28,29}$ Nevertheless, these metals involve in most cases acidic/corrosive salts with counter anions that do not participate in the reaction but can increase safety requirements (oxidizing agents or corrosion risks). ${ }^{8}$ Sulphates, carbonates, oxides and acetates are considered as a safer alternative, however, their use is challenged by poor solubility or hydrolysis.,10 In addition, the presence of such salts in the effluents can sometimes be restricted by environmental regulations leading, in turn, to higher manufacture costs. ${ }^{6}$

With all safety and environmental requirements carefully addressed, an economical assessment can be initiated after a process synthesis (i.e. after establishing the main sequence of process operations) by estimating the production cost. The first step is to estimate the production cost of the material, including raw materials, solvents, and energetic cost, as well as administrative, marketing and maintenance costs. Currently, retail prices (production cost and mark-up) of some MOFs are to high being only affordable for research purposes. ${ }^{30}$ Decreasing their price is a pre-requisite when considering larger-scale productions. Although several chemical companies (BASF) or start-up companies have advertised the largescale production of MOFs, there is no public information available for researchers or end-users about the price of a given MOF when considering its large-scale production for a given application. Several academic research groups have recently addressed the question of MOF production cost. For instance, DeSantis et al. estimated the production cost for four different MOFs by a techno-economic assessment (TEA). ${ }^{31}$ Overall, it was concluded that with process optimization, higher yields, and lower linker and metal precursor price, the cost could be brought down to less than $10 \$ / \mathrm{kg}$ with a production scale of 2500 tons per year. ${ }^{31}$ More recently, Luo et al. ${ }^{32}$ conducted a TEA and life cycle analysis (LCA) of the rapid aqueousbased synthesis of UiO-66- $\mathrm{NH}_{2}$ comparing it to the solvothermal pilot-scale route. Both environmental impact and cost were compared, being the aqueous based synthesis the lower cost option with a value of $15.8 \$ / \mathrm{kg}$ (for the estimation at $1 \mathrm{~kg}$ function unit scale instead of a yearly production capacity). ${ }^{32}$ The potential commercialization of this material seems feasible, although a proof of concept of its production at the pilot-scale needs to be established in the near future. To the best of our knowledge the determination of MOF production cost done by upscaling an established process is yet to be reported. Extensive attention should particularly be given to address critical scale-up problems (e.g. proper reactor geometry, mixing speed, mass transfer, and heat transfer) that can directly impact the process efficiency, impacting the feasibility of the industrial production, and raising safety and environmental issues. ${ }^{15,33,34}$

Among the vast list of benchmark MOFs, aluminum polycarboxylate materials are considered as among the best candidates due to the combination of low-cost abundant raw sources and the possibility to produce these materials in water. The use of abundant, non-toxic metal ions is regarded as promising due to their low cost. Among them, aluminum as shown to be promising for the production of highly stable performant MOFs. ${ }^{8}$ Thus, we have selected as a model case for the economical assessment the robust prototypical bioderived Al-dicarboxylate MOF, MIL-160(Al) that has shown promises

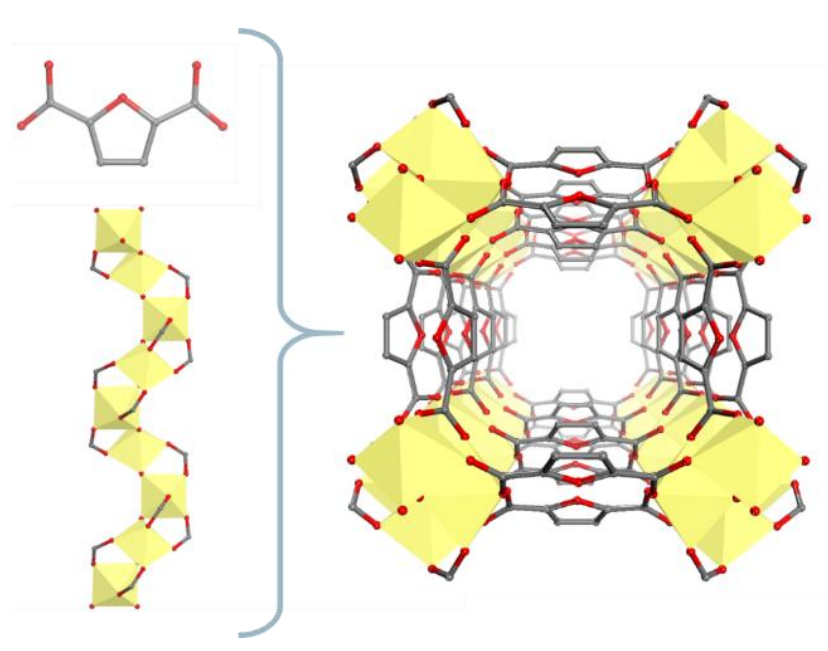

Fig. 1 - Schematic view of the MIL-160(Al) structure with the Al polyhedra, oxygen and carbon atoms in yellow, red, and black, respectively (for simplification hydrogen atoms are not represented). 


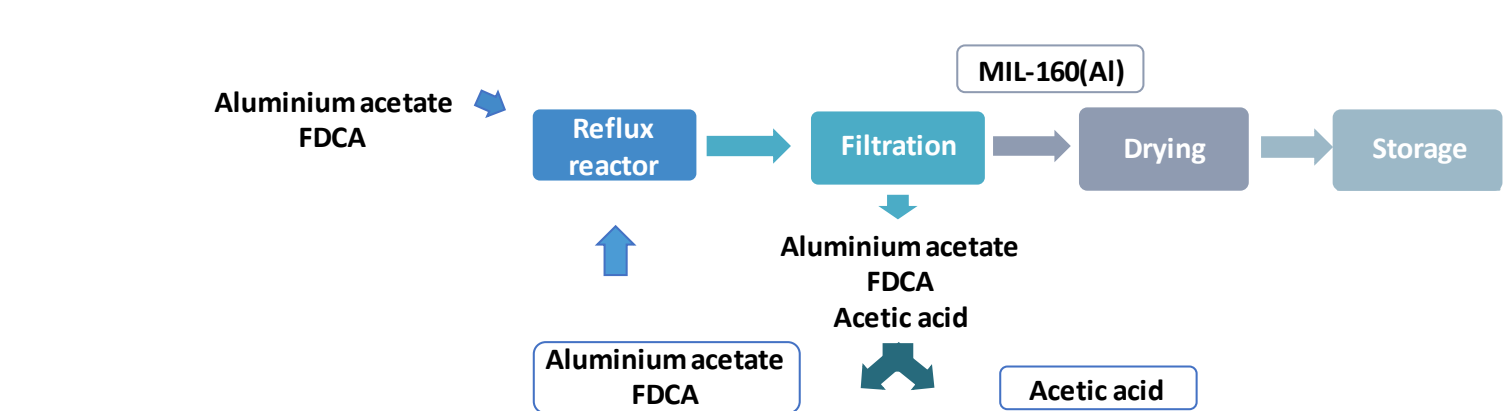

Fig. 2 - Simplified block diagram of the large-scale process developed for production cost calculations of MIL-160(Al). The established process was based on the tests already performed in a pilot lab-scale $30 \mathrm{~L}$ reactor.

for several potential applications such as heat reallocation or $\mathrm{CO}_{2}$ capture, among others. ${ }^{26,35-40}$ This MOF was previously scaled-up to $400 \mathrm{~g}$ using a $2 \mathrm{~L}$ glass-lined reactor based on an optimized green ambient pressure synthesis protocol. ${ }^{41} \mathrm{MIL}-160(\mathrm{Al})$, which structure is isostructural to the $\mathrm{Al}$ isophthalate $\mathrm{CAU}-10(\mathrm{Al}),{ }^{42,43}$ is built up from helical chains of cis-connected $\mathrm{AlO}_{4}(\mathrm{OH})_{2}$ octahedra connected to 2,5-furandicarboxylic acid (FDCA) delimiting a 3D framework with square-shaped 1D microporous channels of ca. $6 \AA$ A, Fig. 1. The FDCA five-membered ring aromatic ligand exhibits an $O$ heteroatom, which combined with the acidic $\mathrm{OH}$ groups from the inorganic chains leads to a high hydrophilic character and a significant surface area (1150 $\left.\mathrm{m}^{2} \mathrm{~g}^{-1}\right)$ and pore volume $\left(0.46 \mathrm{~cm}^{3} \mathrm{~g}^{-1}\right) .{ }^{41}$ Most importantly for the present study, the use of FDCA, a bio-sourced linker based on the oxidation of 5-(hydroxymethyl)furan2-carbaldehyde (HMF), a fructose base material that is used to produce polyethylene furanoate, a renewable plastic, could make this MOF potentially lowcost. ${ }^{44}$ Besides, the synthesis of MIL-160(Al) is easily achieved by adding FDCA to the metal source in an aqueous solution, under ambient pressure in a water-based synthesis (reflux for 26 hours ${ }^{45}$. The aluminum source used is in the form of acetate leading to the formation of acetic acid instead of highly acidic and corrosive counter anions (i.e. chlorides or nitrates). This means that the safety constraints could be easily met and that the equipment construction material will not be expensive. Another advantage is the very good STY that can be obtained by this synthetic route i.e., $185 \mathrm{~kg} \mathrm{~m}^{-3}$ day 1.41

For the calculation of the production costs, estimated in this work two annual industrial production capacities, 100 tons/year and 1 kton/year, have been considered. These values were established from the potential application of MIL-160(Al) as an adsorbent material with high performance but higher price. The market size of zeolites in adsorbent applications is estimated to bein the order of hundreds of million US dollars ${ }^{46}$ which accounts for less than $1 / 6$ of the total market size of zeolites that is estimated to reach a total volume of 6.2 billion USD dollars in 2027 . We have herein foreseen that a small part of this market can be easily taken by MOFs if the price versus performance becomes acceptable. The influence of the production scale value was finally compared to have a comprehensive approach to the impact of this crucial parameter on the production cost and, consequently, on the possible industrialization. In addition, a preliminary sensitivity analysis was done to understand the influence of the parameters in the cost analysis.

\section{Methods}

\section{Pilot-scale synthesis}

The process was scaled-up by performing the reaction in a pilot-scale $30 \mathrm{~L}$ glass reactor from Pignat using mechanical stirring. Aluminum hydroxide acetate and FDCA were stirred in deionized water in the molar ratio $1: 1: 56$. The mixture was heated to reflux for 26 hours, after which the white product was isolated and cooled untilroom temperature using a Nutsche filter. The resulting MOF was washed directly in the filter removing acetic acid as side product and unreacted FDCA with water and ethanol before being dried in a vacuum oven for 16 hours at $200^{\circ} \mathrm{C}$ (yield $=93 \%$ and STY $=185 \mathrm{~kg} \mathrm{~m}^{-}$ ${ }^{3}$ day $^{-1}$ ). The obtained MIL-160(Al) structure was confirmed by X-ray powder diffraction (PXRD) (Fig. S1 ESI). Nitrogen adsorption-desorption isotherms were measured to assess the material porosity (Fig. S2 ESI). Thermogravimetric analysis (Fig. S3 ESI) showed that the framework was thermally stable under oxygen up to $673 \mathrm{~K}$, which is in agreement with previously obtained results for smaller scale synthesis ${ }^{26}$. The particle size was also in accordance with previous results from the literature (Fig. S4 ESI). ${ }^{41}$

\section{Process description}

With the data collected from laboratory pilot-scale tests the synthesis and process design can be constructed for an industrialscale production. It can be described using a simplified block diagram, starting by feeding the batch reflux reactor with the raw materials i.e., linker, solvent (water), and metal source, Fig. 2. The solid is subsequently recovered by filtration and then is dried and stored. At higher production scales, additional steps can be considered to guaranty the feasibility of the process. For instance, effluents composition can contain valuable or toxic materials that must not be disregarded, requiring additional recovery/treatment steps. In the case of MIL-160(Al) synthesis, an effluent pre-treatment it is not required, given the non-toxic and non-corrosive character of the materials in the stream (un-reacted precursors and side products formed). Nevertheless, the recovery and reuse of the raw materials from this stream could eventually decrease the cost, especially in the case of low yield reactions and/or high precursors price. To this end, a potential additional purification step was studied to avoid the recirculation of unwanted materials along with the unreacted precursors, since this might interfere with the final quality of the 
produced MOF. In our case, the recovery of the unreacted raw materials is only possible if acetic acid, produced from the reaction of aluminum acetate with FDCA, is separated from water in order to keep the chemical equilibrium in the reactor favoring the formation of MIL-160(Al). The separation of acetic acid from the aqueous stream is usually done by solvent extraction, which requires the use of a solvent, i.e. methyl t-butyl ether (MTBE) or similar. Consequently, the recovery of the unreacted precursors was simulated by the concentration of the filtration effluent, removing the solvents and acetic acid, until a lower enough amount, will not impact the reaction equilibrium, when the precursors are reintroduced in the reactor. The feasibility of this process was not tested in the pilot-scale trials but is based on heuristics and basic chemical engineering knowledge allowing the estimation of the economic impact of solvent/raw materials recovery step. Once the whole process was defined, process design can be done by establishing mass and energy balance for two annual production capacities (100 tons and 1kton a year of MIL-160(Al)) taking into consideration both the recirculation and non-recirculation of the unreacted precursors, followed by sizing of the process equipment.

The type of equipment was chosen based on the process requirements and chemical engineering heuristic rules. ${ }^{47-49}$ One of the most important pieces of equipment to be considered, besides the reactor, is the filter. The choice of adequate filtration equipment is essential to the final quality of MOF that is produced. In order to have a material within the range of the expected performances ${ }^{41}$, washing the product directly in the filter with water and ethanol is required to remove the excess of unreacted precursors that could eventually block the pores decreasing the specific surface area and/or slowing down the sorption diffusivity. The choice of each piece of equipment was carefully considered to allow for cost determination without compromising the final product. A brief list of selected equipment and corresponding justification is referred in Tab. 1. The remaining equipment (pumps, agitator, cyclone, etc.) is detailed in Tab. S1 ESI. The estimation of the equipment cost was made considering the construction material that was defined based on corrosion data. ${ }^{50}$ In the present case, SS316 stainless steel was chosen because, although expensive, avoids any possible short-term corrosion problems and increases equipment life span. With all the data from the equipment, Aspen V8 simulations were run for reactor, condensers, and for the single effect evaporator, while for the remaining equipment the design was based on engineering

Tab. 1 - List of selected equipment, and respective heuristic rules.

\begin{tabular}{|c|c|c|}
\hline Equipment & Type & Justification \\
\hline Filter & Filter press & $\begin{array}{l}\text { Most used batch filter } \\
\text { adequate for medium filtering } \\
\text { speeds; Allows washing } \\
\text { directly in the filter; }\end{array}$ \\
\hline Dryer & $\begin{array}{l}\text { Atmospheric } \\
\text { batch tray dryer }\end{array}$ & $\begin{array}{l}\text { Most used batch dryer for } \\
\text { granular materials }\end{array}$ \\
\hline \multirow[t]{2}{*}{$\begin{array}{c}\text { Solid } \\
\text { transporter }\end{array}$} & Screw conveyor & $\begin{array}{c}\text { Abrasive or/and sticky } \\
\text { materials for lower densities } \\
\text { than } 150 \mathrm{ft}\end{array}$ \\
\hline & $\begin{array}{l}\text { Pneumatic } \\
\text { transport }\end{array}$ & Small particles of low density \\
\hline
\end{tabular}

4 | J. Name., 2012, 00, 1-3 calculations for equipment sizing and the price obtained through two available databases. ${ }^{51,52}$ The cost values were updated with the chemical engineering plant cost indexes (Tab. S2 ESI).

\section{Economic assessment}

\section{Fixed capital investment}

With all the equipment sized, the fixed capital investment (FI) can be determined by using the relationship shown in Eq. 1 . The fixed capital investment accounts for all the required investment in durable capital goods, as machinery, buildings, and project. Here, the fixed capital investment was determined by the percentage of delivered-equipment cost method, where $C_{B E}$ is the equipment cost (determined by the size of each equipment and corresponding information from ASPEN and databases), and $f_{2}, \ldots f_{9}, f_{1}^{\prime}-f_{2}^{\prime}$ and $f$ "are based on previously defined typical values used in the chemical industry (Tab. S3 and Tab. S4 ESI). With the established percentages for each $f_{n}$ and the equipment cost, the fixed capital investment can be estimated. Other methods could be considered as Lang's method $^{53}$ or William's rule ${ }^{47}$ which are either less precise or require similar production facilities to operate, and are thus not viable options.

$$
\begin{gathered}
F I=C_{\text {direct }}+C_{\text {indirect }} \\
=\left[C_{B E}\left(1+f_{2}+\cdots+f_{9}\right)+C_{\text {direct }}\left(1+f_{1}^{\prime}+f_{2}^{\prime}\right)\right]\left(1+f^{\prime \prime}\right) \\
f_{2}, \ldots f_{9}-\text { Percentage over base equipment }
\end{gathered}
$$

$f_{1}^{\prime}$ - Percentage over the project and respective inspection

$f_{2}^{\prime}$ - percentage for construction works

$$
f^{\prime \prime} \text { - risk provision }
$$

\section{Production cost}

The global production cost needs also to account for the recovery of the fixed capital investment made during the construction of the chemical plant, considering the defined depreciation times ( 3 years for the project, 10 years for the equipment, 25 years for buildings), and, to the best of our knowledge, this is the first time that such a complete approach is presented for a MOF production. This means that the cost accounts for all that is required to make the production operable during an established amount of time, which is a defined economic evaluation period. Usually, this analysis is done for a 10 years' timeline during which it is expected that a return on investment is achieved (including the payment of the principal and interest of bank loans) and profit is obtained. The price of chemical reagents and utilities, the cost of labor, maintenance, and repairs, packaging, storing, control, shipping, social charges, taxes, depreciation, insurance, rent, and others, were included within the production cost estimation. Each parcel was estimated based on market prices or relationships established by heuristic rules. 
Tab. 2 - Different costs considered for the estimation of the production cost and respective assumptions ${ }^{47}$.

\begin{tabular}{|c|c|c|c|}
\hline \multirow[t]{14}{*}{ Manufacturing costs } & \multirow[t]{2}{*}{ Direct } & \multicolumn{2}{|l|}{ Raw materials } \\
\hline & & Utilities & \\
\hline & & $\begin{array}{l}\text { Operating labor and } \\
\text { supervision }\end{array}$ & \\
\hline & & Maintenance and repairs & $3-10 \%$ Fixed capital investment \\
\hline & & Patents and royalties & $2 \%$ Manufacturing costs \\
\hline & & Operating supplies & $15 \%$ Maintenance \\
\hline & Indirect & Quality control & $60 \%$ Labor \\
\hline & & Packaging & \\
\hline & & Technical service & \\
\hline & & $\begin{array}{l}\text { Security, sales and storing } \\
\text { services }\end{array}$ & \\
\hline & Fixed & Depreciation & \\
\hline & & Taxes & $2 \%$ Fixed capital investment \\
\hline & & Insurance & \\
\hline & & Rent & $1 \%$ Fixed capital investment \\
\hline \multirow[t]{3}{*}{ General expenses } & Administrative expenses & & \\
\hline & $R \& D$ & & \\
\hline & Financial charges & & \\
\hline
\end{tabular}

Several relationships considered in the calculations are referred to in Tab. 2. The values of each parcel, which were initially estimated based on market values, were confirmed at the end by typical engineering relationships regarding the total manufacturing cost (the major parcel of the production cost), Tab. 3. It is important to consider the scale of production since this significantly impacts the production cost. By increasing this value, the cost is expected to decrease due to economics of scale. Thus, for a brief comparison, of this effect, 100 tons/year and 1 kton/year were considered. However, to determine the real capacity to be installed in a plant, the demand for the product needs to be effectively known.

Tab. 3- Typical relationships between different parcels of the production cost and the manufacturing costs that need to be confirmed after the calculation of this parcels by using market values.

\begin{tabular}{lc}
\hline Parcel cost & $\begin{array}{c}\text { Relationships with } \\
\text { manufacturing cost }\end{array}$ \\
\hline Raw materials & $<50 \%$ \\
\hline Operating labor & $5-25 \%$ \\
\hline Operating supervision & $10-25 \%$ \\
\hline Utilities & $5-20 \%$ \\
\hline
\end{tabular}

Tab. 4 - Different values considered for the production cost estimation.

\begin{tabular}{lc}
\hline & Values considered \\
\hline Linker price & $10 \$ \mathrm{~kg}^{-144}$ \\
\hline Yield & $93 \%{ }^{41}$ \\
\hline Rent & $0.5 \mathrm{RMD} \mathrm{m}^{-2} \mathrm{day}^{-154}$ \\
\hline Electricity price & $0.08 \$ \mathrm{kWh}^{-155}$ \\
\hline Process water & $0.8 \$ \mathrm{ton}^{-155}$ \\
\hline Ethanol & $1.3 \$ \mathrm{~m}^{-355}$ \\
\hline
\end{tabular}

In addition, the location considered for the project was based on the proximity of raw materials factories and the cost of utilities. In this perspective, the Asian continent is usually more competitive, with China being the one showing higher economic advantages with shorter transport distances required for the goods and lower rent and taxes. The linker price, yield, and location values considered can be seen in Tab. 4. These values are crucial for the production cost. In addition, the installation in China is usually preferred due to lower salaries. However, regarding the most recent trends, the US and Europe could start being considered for the installation of industrial facilities which can be seen by the ease of doing business index, profit taxes, labor taxes and contributions (\% over profits) and other business indexes, if the precursors production is also set in the correspondent continent. ${ }^{56}$

\section{Results and discussion}

\section{Annual capacity effect}

The annual capacity effect on production cost was studied first. At this stage, this comparison was done without considering any recirculation process of the unreacted raw materials. It is expected that with the increase in the production volume the overall cost is lower. This can be explained by comparing the effect on the fixed investment. For example, regarding one of the main equipment in the fixed capital investment, the reactor. When increasing the production volume, the reactor size will increase together with the investment needed (a small increase is also expected for the land space). 
Tab. 5- Effect of the annual capacity on the reactor volume and cost.

\begin{tabular}{lll}
\hline Annual capacity & Volume $\left(\mathrm{m}^{\mathbf{3}}\right)$ & Price $(\mathbf{)})$ \\
\hline $\mathbf{1 0 0}$ tons/year & $4 \mathrm{~m}^{3}$ & $1.0 \mathrm{M} \$$ \\
\hline $\mathbf{1}$ kton/year & $34 \mathrm{~m}^{3}$ & $1.6 \mathrm{M} \$$ \\
\hline
\end{tabular}

However, the raw materials and pieces (valves, sensors, tubes, etc.) needed to build a reactor do not increase linearly with the reactor volume. Thus, the investment for a bigger reactor will be lower per unit of MOF produced, decreasing the capital costs per unit produced. Therefore, when the amount of product being sold increases, the cost to produce each unit (mass or volume) is lower, due to this non-linear dependence of the equipment during scale-up. That effect can be illustrated by the price dependence of the reactor size in Tab. 5. As a result, for 100 tons/year the production cost is estimated to $55.2 \$ / \mathrm{kg}$. The decrease in cost with scale is $47 \%$ reaching $29.5 \$ / \mathrm{kg}$ for $1 \mathrm{kton}$ production. However, these values are also highly dependent on the price of raw materials considered, which is going to be discussed further. The value of each cost parcel for the two-yearly capacities are presented in Tab. S5 ESI.

\section{Solvent and raw materials recovery}

The production cost was recalculated considering the recovery of unreacted raw materials, for an annual capacity of $1 \mathrm{kton} /$ year. To recover the raw materials, almost all solvent volume removal is needed. To this end, evaporation was considered using an single effect evaporator. The amount of FDCA and aluminum acetate that needs to be supplied will be lower and, consequently, the raw material cost per unit of MOF will decrease, from $13.9 \$ / \mathrm{kg}$ to 13.2 $\$ / \mathrm{kg}$. This decrease is small due to the yield of the reaction being high (93\%). However, the decrease is not sufficient to outweigh the energetic consumption required to evaporate the solvent in order to concentrate the recirculated stream (1132 kg water/hour, $323 \mathrm{~kg}$ ethanol/hour and $148 \mathrm{~kg}$ of acetic acid/hour), which is around 3.1 $\mathrm{MJ} /$ hour.

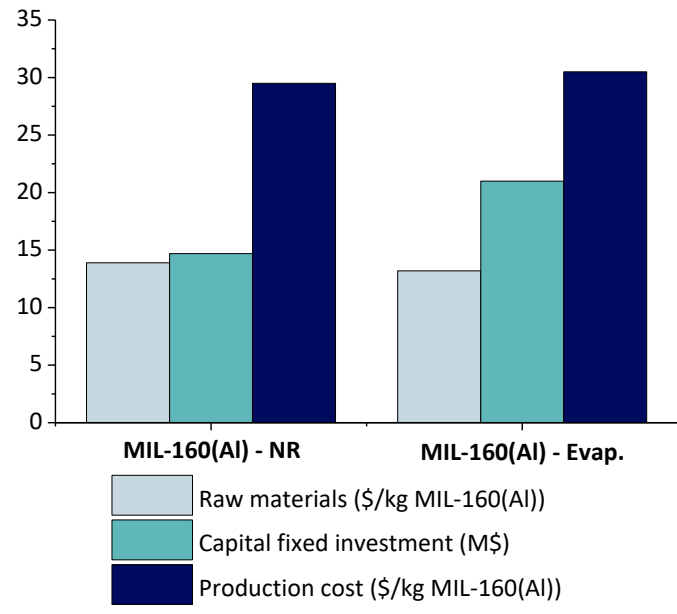

Fig. 3 - Raw materials price, production cost and fixed investment values calculated for the different recovery processes considered (NR - no recovery and Evap.) for MIL-160(Al) production.
Even if the impact on the total production cost in this process is low (Fig. 3), when considering higher scales or lower yields, this could be of importance to further decrease the production cost.

Thus, when increasing the scale of the process, further studies on the materials recirculation as well as solvent recovery will be necessary due to their role in the economic viability of the process. The recovery could also have a more significant impact with a higher FDCA price. However, this price is expected to reach in a near future values much below $10 \$ / \mathrm{kg}^{44}$ a consequence of the use of FDCA in the large-scale production of bio-polymers, a growing market, leading to a strong increase in demand. As so, the price of ligand here considered was $10 \$ / \mathrm{kg}^{44}$ as an example. Besides, considering higher market values for the FDCA price $(<100 \$ / \mathrm{kg})$, the impact of the unreacted precursors' recirculation is still of low significance, Fig. 4.

The production cost of MOF is indeed highly dependent of the linker price and here only a further linker price decrease could lead to production costs meeting the goal previously referred by the Advanced Research Projects Agency (ARPA-E) - Energy for gas storage applications of $10 \$ / \mathrm{kg} .{ }^{31,57}$

Taking into consideration the values from Tab. 4, with a $93 \%$ reaction yield and an FDCA price of $10 \$ / \mathrm{kg}$ the mean value of production costs was found to be $29.5 \$ / \mathrm{kg}$, for a 1 kton yearly production capacity plant without the recovery of the unreacted raw materials. The production capacity of the plant is not fully used at the beginning of the project, i.e. the occupancy level is not complete (this is typical in the chemical industry), then the production costs will be higher at this stage. We calculated this variation and found values from $32 \$ / \mathrm{kg}$ to $29 \$ / \mathrm{kg}$, with occupancy level changes from $80 \%$ to $100 \%$ (in the final project evaluation years).

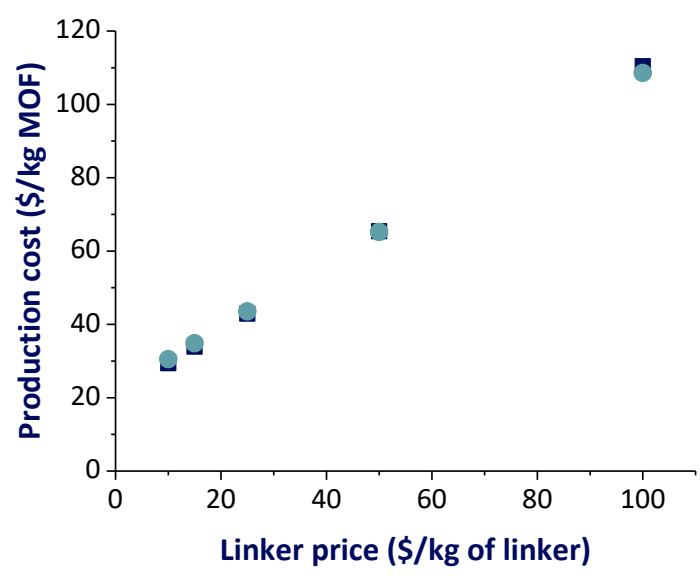

Fig. 4- Production cost dependence of MIL-160(Al) at kton scale as a function of the FDCA price (.) with no unreacted raw materials recovery and (॰) with unreacted raw materials recovery. 


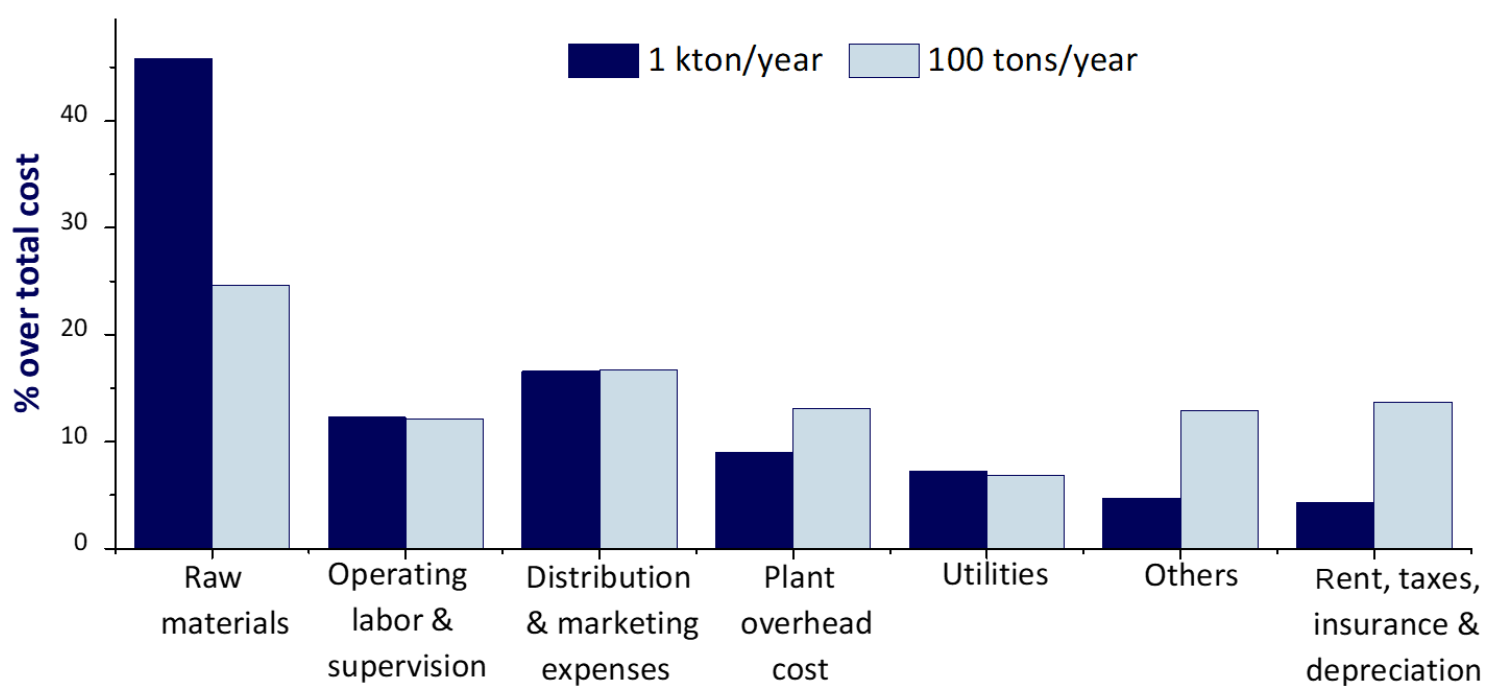

Fig. 5- Different weights of the parameters considered per unit of MOF produced for two different production capacities estimated 100 tons/year and 1 kton/year

In addition, a high STY value is also relevant for a low production cost. In MIL-160(Al) the STY is high being in the order of magnitude commonly found in the industry. ${ }^{25}$ Nevertheless, the overall STY that accounts for filtration and washing process calculated in this work is lower than the reaction STY $\left(185 \mathrm{~kg} \mathrm{~m}^{-3} \mathrm{day}^{-1}\right)$, however it is still acceptable(i.e. of $\left.38 \mathrm{~kg} \mathrm{~m}^{-3} \mathrm{day}^{-1}\right) .^{41}$ This overall value is more realistic than the bare STY usually considered in previous MOF production reports, as the filtration and washing steps are crucial steps in MOF production to obtain a product with high purity and performance. However, the construction of a green process together with low cost solvents is possible for this prototypical MOF, thus, the cost was not highly influenced by these steps.

The economic analysis performed suggests that the aqueous-based solution synthetic route has a production cost value in the same range as the ones previously estimated for benchmark MOFs such as

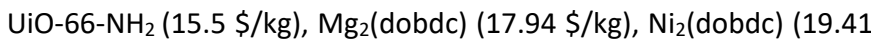
$\$ / \mathrm{kg})$, HKUST-1 ( $\left.\mathrm{H}_{3} \mathrm{btc}\right)(32.93 \$ / \mathrm{kg})$, and MOF-5 ( $\left.\mathrm{H}_{2} \mathrm{bdc}\right)(13.85 \$ / \mathrm{kg})$ in a 2.5 kton scale. ${ }^{32,31}$ However, if one would recalculate these other costs following our method and in the scale considered, these values might be slightly higher since in our case we considered, for the first time in a MOF cost estimation study, a larger number of parameters that are essential for the implementation and operation of a new chemical plant. As it can be seen in Fig. 5 the impact of these parameters is far from being negligible.

As expected, the most relevant weight is attributed to the raw materials, which is in accordance with what is expected in the chemical industry. The weight of this parcel changes drastically with the scale, being more dominant with larger scales since the other parcels tend to decrease their weight, e.g. the unit costs decrease.

\section{Sensitivity analysis}

In order to better understand the impact of different parameters such as fixed investment, yield, administrative expenses, operating labor, and supervision, a simplified sensitivity analysis was performed, Fig. 6 . The results could be used as a guide on further improvement in the overall process for a significant cost reduction. One can point out, for example, that even if the fixed capital investment varies by $20 \%$, this does not have a significant impact on the final cost. However, the operating labor cost variation can have a more serious impact on the final cost. In addition, any decrease in the yield shows also a great impact due to the increase in raw material cost to achieve the same production. This will be more noticeable with a higher linker price, highlighting the importance of achieving a high yield process or the use of a purification step for the filtration effluent. The amount of solvent used has a lower impact, as expected from the low cost of water and ethanol considered here (0.8 $\$ /$ ton and $1.3 \$ / \mathrm{m}^{3}$, respectively).

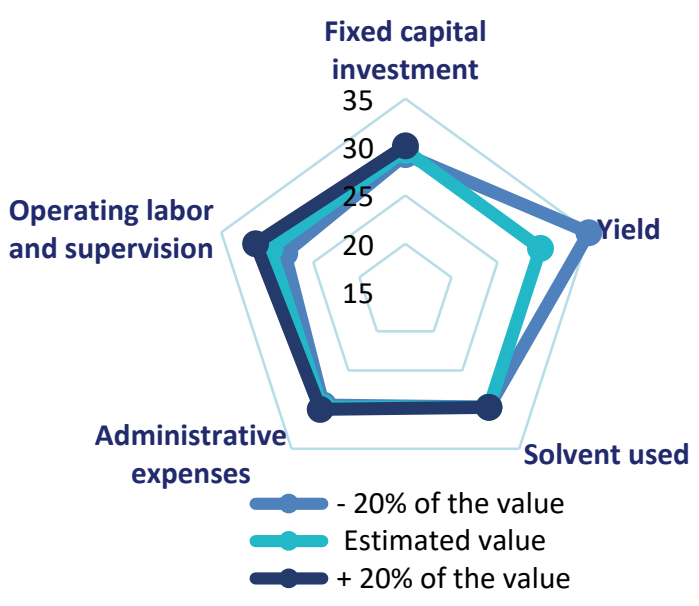

Fig. 6 - Sensitivity analysis of production cost, with the fluctuation $\pm 20 \%$, represented by blue and light blue, compared to the original estimated value. 


\section{Conclusion}

A production cost estimation of MOF made under batch green ambient pressure conditions was performed for the prototypical MIL-160(Al) including for the first time a full economic analysis, considering the investment in a production plant. The scalability of the synthesis protocol followed was first proven by performing the synthesis of a high-quality sample using a pilot-lab scale $30 \mathrm{~L}$ reactor with water as a solvent, in order to meet the requirements of a low-cost, non-toxic industrial production. This is translated to a high overall STY of $38 \mathrm{~kg} \mathrm{~m}^{-3}$ day $^{-1}$, that includes all steps of the synthesis and recovery of the MOF.

Calculations considering two different production scales have demonstrated the impact of this factor in the production cost with a significant decrease when the manufacturing scale is higher. A price lower than $30 \$ / \mathrm{kg}$ for $1 \mathrm{kton}$ year production was estimated while for 100 tons/year it exceeded $50 \$ / \mathrm{kg}$. In these calculations, it was seen that raw material cost accounts for a large part of the total cost while the investment for the construction of the production plant, that accounted for a period of 10 years, had a lower impact. As a consequence, if a decrease in the production cost is expected, the main parameter that would drive the MOF's production cost would be the linker price. In our case, one can expect that a linker price of less than $10 \$ / \mathrm{kg}$ could lead to the cost of MIL-160(Al) meeting the objective of $10 \$ / \mathrm{kg}$ in a view of adsorption/separation applications. This study highlights the potential of benchmark MOFs, here MIL-160, for industrial batch production and commercialization, while identifying important parameters to take into account in MOF production design, such as the choice of low-cost precursors, green solvents, ambient pressure, etc. It also demonstrates the possibility for MOFs to reach reasonable competitive prices highlighting their potential to reach the market for large-scale applications.

\section{Author Contributions}

M.I.S. contributed to the economic analysis and participated in the writing of the article. E.G. contributed to the synthesis and characterization of the MIL-160(Al) in the pilot-scale $30 \mathrm{~L}$ reactor, and participated in the writing of this article. F.N., M.P. and C.S. were the co-coordinators of the whole study and led the writing of the article as well as closely supervising the synthesis and characterization of the work.

\section{Conflicts of interest}

There are no conflicts to declare.

\section{Acknowledgements}

The authors would like to acknowledge the European Community Horizon 2020 Program (H2020-NMBP-2017-twostage) for funding the research presented in this article under
Grant Agreement No. 760801-2 (project Nemosine). MLP and MIS acknowledge Fundação para a Ciência e a Tecnologia (FCT) for funding to the research centre CERENA (UIDB/04028/2020, UIDP/04028/2020).

\section{Notes and references}

B. F. Hoskins and R. Robson, J. Am. Chem. Soc., 1989, 111, 5962-5964.

G. Férey, Chem. Soc. Rev., 2008, 37, 191-214.

D. Zhao, P. K. Thallapally, C. Petit and J. Gascon, ACS Sustain. Chem. Eng., 2019, 7, 7997-7998.

P. K. Bharadwaj, P. Feng, S. Kaskel and Q. Xu, Chem. - An Asian J., 2019, 14, 3450-3451.

$\mathrm{H}$. Vogel, in Chemical engineering and chemical process technology, ed. E. of L. S. S. (EOLSS), vol. IV.

P. A. Julien, C. Mottillo and T. Friščić, Green Chem., 2017, 19, 2729-2747.

R. Del Angel, G. Mouchaham, F. Nouar, A. Tissot, C. Serre, 'Robust and Environmentally Friendly MOFs'. Metal Organic Frameworks in Biomedical and Environmental Field, P. Horcajada, S. R. Macias, Springer International Publishing, 2021.

M. Gaab, N. Trukhan, S. Maurer, R. Gummaraju and U. Müller, Microporous Mesoporous Mater., 2012, 157, 131136.

Ren, X. Dyosiba, N. M. Musyoka, H. W. Langmi, M. Mathe and S. Liao, Coord. Chem. Rev., 2017, 352, 187-219.

A. D. G. Firmino, R. F. Mendes, J. P. C. Tomé and F. A Almeida Paz, Met. Fram., 2018, 57-80.

C. S. Slater and M. Savelski, J. Environ. Sci. Heal. - Part A Toxic/Hazardous Subst. Environ. Eng., 2007, 42, 15951605.

C. P. Ashcroft, P. J. Dunn, J. D. Hayler and A. S. Wells, Org. Process Res. Dev., 2015, 19, 740-747.

F. P. Byrne, S. Jin, G. Paggiola, T. H. M. Petchey, J. H. Clark, T. J. Farmer, A. J. Hunt, C. Robert McElroy and J. Sherwood, Sustain. Chem. Process., 2016, 4, 7.

A. D. Curzons, D. C. Constable and V. L. Cunningham, Clean Technol. Environ. Policy, 1999, 1, 82-90.

S. Kumar, S. Jain, M. Nehra, N. Dilbaghi, G. Marrazza and K. H. Kim, Coord. Chem. Rev., 2020, 420, 213407.

U. Ryu, S. Jee, P. Chandra, J. Shin, C. Ko, M. Yoon, K. Sung and K. Min, Coord. Chem. Rev., 2021, 426, 213544.

D. Lenzen, P. Bendix, H. Reinsch, D. Fröhlich, H. Kummer, M. Möllers, P. P. C. Hügenell, R. Gläser, S. Henninger and N. Stock, Adv. Mater., 2018, 30, 1-6. Y. Pan, Y. Liu, G. Zeng, L. Zhao and Z. Lai, Chem. Commun., 2011, 47, 2071-2073.

A. F. Gross, E. Sherman and J. J. Vajo, Dalt. Trans., 2012, 41, 5458-5460. 

Eur. J., 2013, 19, 11139-11142. G. Majano and J. Pérez-Ramírez, Adv. Mater., 2013, 25, 1052-1057.

22 S. Cadot, L. Veyre, D. Luneau, D. Farrusseng and E. Alessandra Quadrelli, J. Mater. Chem. A, 2014, 2, 1775717763.

M. Sánchez-Sánchez, N. Getachew, K. Díaz, M. Díaz-García Y. Chebude and I. Díaz, Green Chem., 2015, 17, 1500-1509.

H. Chevreau, A. Permyakova, F. Nouar, P. Fabry, C. Livage, F. Ragon, A. Garcia-Marquez, T. Devic, N. Steunou, C. Serre and P. Horcajada, CrystEngComm, 2016, 18, 4094-4101.

B. Yilmaz, N. Trukhan and U. Müller, Chinese J. Catal., 2012, 33, 3-10.

26 A. Cadiau, J. S. Lee, D. Damasceno Borges, P. Fabry, T. Devic, M. T. Wharmby, C. Martineau, D. Foucher, F. Taulelle, C. H. Jun, Y. K. Hwang, N. Stock, M. F. De Lange, F. Kapteijn, J. Gascon, G. Maurin, J. S. Chang and C. Serre, Adv. Mater., 2015, 27, 4775-4780.

S. B. Peh, Y. Wang and D. Zhao, ACS Sustain. Chem. Eng., 2019, 7, 3647-3670.

28 S. Yuan, L. Feng, K. Wang, J. Pang, M. Bosch, C. Lollar, Y. Sun, J. Qin, X. Yang, P. Zhang, Q. Wang, L. Zou, Y. Zhang, L. Zhang, Y. Fang, J. Li and H. C. Zhou, Adv. Mater.

J. J. Low, A. I. Benin, P. Jakubczak, J. F. Abrahamian, S. A. Faheem and R. R. Willis, J. Am. Chem. Soc., 2009, 131, 15834-15842.

30 J. Liu, P. K. Thallapally, B. P. McGrail, D. R. Brown and J. Liu, Chem. Soc. Rev., 2012, 41, 2308-2322.

D. DeSantis, J. A. Mason, B. D. James, C. Houchins, J. R. Long and M. Veenstra, 2019, 15, 50.

H. Luo, F. Cheng, L. Huelsenbeck and N. Smith, J. Environ. Chem. Eng., 2021, 9, 1-39.

C. McKinstry, Doctoral dissertation, University of Strathclyde, Glasgow, 2015, 20-29.

J. Harmsen, Industrial Process Scale-up : Scale-Up of Unit Operations, Elsevier, Amesterdam, 1 st editi., 2013.

A. Permyakova, S. Wang, E. Courbon, F. Nouar, N. Heymans, P. D’Ans, N. Barrier, P. Billemont, G. De Weireld, N. Steunou, M. Frère and C. Serre, J. Mater. Chem. A, 2017, 5, 12889-12898.

S. Cui, A. Marandi, G. Lebourleux, M. Thimon, M. Bourdon, C. Chen, M. I. Severino, V. Steggles, F. Nouar and C. Serre, Appl. Therm. Eng., 2019, 161, 114135.

D. Damasceno Borges, P. Normand, A. Permiakova, R. Babarao, N. Heymans, D. S. Galvao, C. Serre, G. De Weireld and G. Maurin, J. Phys. Chem. C, 2017, 121, 26822-26832.

X. Wu, W. Wei, J. Jiang, J. Caro and A. Huang, Angew. Chemie - Int. Ed., 2018, 57, 15354-15358.

39 P. Brandt, A. Nuhnen, M. Lange, J. Möllmer, O. Weingart and C. Janiak, ACS Appl. Mater. Interfaces, 2019, 11 17350-17358.
41

42

44
A. Permyakova, O. Skrylnyk, E. Courbon and M. Affram, ChemSusChem Eur., 2017, 160, 1419-1426.

H. Reinsch, M. A. Van Der Veen, B. Gil, B. Marszalek, T. Verbiest, D. De Vos and N. Stock, Chem. Mater., 2013, 25 17-26.

H. Reinsch, S. Waitschat and N. Stock, Dalt. Trans., 2013, 42, 4840-4847.

C. Triebl, V. Nikolakis and M. lerapetritou, Comput. Chem. Eng., 2013, 52, 26-34.

A. H. Motagamwala, W. Won, C. Sener, D. M. Alonso, C. T. Maravelias and J. A. Dumesic, Sci. Adv., 2018, 4, 1-8.

F. business Insights, Zeolite Market Size, Share \& COVID-19 Impact Analysis, By Type (Natural [By Application \{Construction \& Building Materials, Animal Feed, Wastewater Treatment, Soil Remediation, and Others\}], Synthetic [By Application \{Detergents, Catalysts, and Adsorbents,

https://www.fortunebusinessinsights.com/industryreports/zeolite-market-101921, (accessed 5 January 2020).

M. S. Peters and Klaus D. Timmerhaus, Plant Design and Economics for Chemical Engineers, Elizabeth A.Jones, 5th edn., 2003.

S. M. Couper, James R., Penney, W. Roy, Fair, James R. Walas, Chemical Process Equipment Selection and design : Rules of thumb : Summary, 2005.

W.D. Seider, D.R. Lewin, J.D. Seader, S. Widagdo, R. Gani, K. Ming Ng, Product and Process design principleSynthesis, Analysis, and Evaluation : Heuristics for Process Synthesis, Wiley, 2010.

Dacapo.com, Corrosion Resistance Table, http://www.dacapo.com/, (accessed 15 June 2020).

Matches, https://www.matche.com/equipcost/Tank.html, (accessed 1 December 2020).

W. R. E. Peters, Max S., Klaus D.Timmerhaus, Equipment cost calculation page - Plant design and economics for chemical engineering,

http://www.mhhe.com/engcs/chemical/peters/data/, (accessed 1 December 2020).

\section{H. J. Lang, Engineering Approach to Preliminary Cost} Estimates, Chem. Eng., 1947, vol. 54.

Property market, China, 2016,

http://www.colliers.com/en-gb/china/about/media/201701-04-ec-property-market-2016-review-and-2017-outlook, (accessed 30 June 2020).

G. D. U. and P. T. Vasudevan and U. of N. Hampshire, 2006.

C. and U. Data for EU, The world bank,

https://data.worldbank.org/?locations=CN-US-EU

ARPA-E. MOVE Program Overview, 2012, https://arpae.energy.gov/sites/, (accessed 10 August 2020). 